\title{
Article \\ Complete Chloroplast Genomes of Three Salix Species: Genome Structures and Phylogenetic Analysis
}

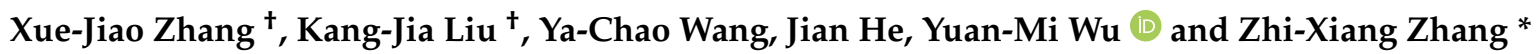 \\ Laboratory of Systematic Evolution and Biogeography of Woody Plants, School of Ecology and Nature, \\ Conservation, Beijing Forestry University, Beijing 100083, China; zxj160501330@163.com (X.-J.Z.); \\ liukangjia@bjfu.edu.cn (K.-J.L.); yachao_wang@bjfu.edu.cn (Y.-C.W.); j.he930724@gmail.com (J.H.); \\ yuanmiwu@163.com (Y.-M.W.) \\ * Correspondence: zxzhang@bjfu.edu.cn \\ † These authors contributed equally to this work.
}

check for updates

Citation: Zhang, X.-J.; Liu, K.-J.; Wang, Y.-C.; He, J.; Wu, Y.-M.; Zhang, Z.-X. Complete Chloroplast Genomes of Three Salix Species: Genome Structures and Phylogenetic Analysis. Forests 2021, 12, 1681. https:// doi.org/10.3390/f12121681

Academic Editor: Gary D. Coleman

Received: 20 September 2021

Accepted: 23 November 2021

Published: 1 December 2021

Publisher's Note: MDPI stays neutral with regard to jurisdictional claims in published maps and institutional affiliations.

Copyright: (c) 2021 by the authors. Licensee MDPI, Basel, Switzerland. This article is an open access article distributed under the terms and conditions of the Creative Commons Attribution (CC BY) license (https:// creativecommons.org/licenses/by/ $4.0 /)$.

\begin{abstract}
High genetic diversity and low differentiation present challenges in taxonomy and systematics of Salix. Chloroplast (cp) genome sequencing is efficient for providing new genomic information and elucidating phylogenetic relationships. Salix spathulifolia Seemen, S. cupularis Rehder, and S. annulifera C.Marquand \& Airy Shaw are three shrubby willows spread in high-altitude regions in western China. In this study, the integrated circular cp genomes were sequenced and analyzed, and a phylogeny of Salix was constructed on the basis of the cp genomes. The results of chloroplast assembly and annotation information were used to characterize genome feature and interspecific variation. The phylogenetic position of the three willows was evaluated using phylogenetic analysis. Full-length cp genomes were $155,566-155,680$ bp with a typical double-stranded circular quadripartite structure, containing one large single-copy region (LSC, 84,431-4552 bp), one small single-copy region (SSC: 16,206-16,221 bp), and two inverted repeats (IR: 27,453-27,461 bp). The cp genomes encoded 130 genes, including 8 rRNA genes, 37 tRNA genes, and 85 protein-coding genes. The guanine-cytosine (GC) content of the overall genome was $36.7 \%$. Comparison among the three willows' cp genomes revealed high similarity. Phylogenetic analysis indicated that $S$. spathulifolia was a basal taxon of clade I, while S. annulifera formed a monophyletic group with S. rorida Laksch.; S. cupularis was sister to S. suchowensis W.C. Cheng and S. psammophila Z. Wang \& Chang Y. Yang. The complete chloroplast genomes of the three willows provides an additional sequence-based resource for studying the phylogeny and evolutionary history of Salicaceae.
\end{abstract}

Keywords: Salix; chloroplast genome; sequence variation; comparative analysis; phylogeny

\section{Introduction}

The chloroplast (cp) is an essential semi-autonomous organelle within the cells of green plants, responsible for carbon fixation, energy conversion, and other important biochemical pathways [1]. Moreover, it possesses its own independent circular genome [2]. The cp genomes of most higher plants are characterized by a quadripartite structure typically consisting of two inverted repeats (IRs) with a length of $20-28 \mathrm{~kb}$, separated by a large single-copy (LSC) region with a length of 80-90 kb and a small single-copy (SSC) region with a length of 16-27 kb. Almost all cp genomes range in size from 120 to $160 \mathrm{~kb}$ [3] with 110-130 uniquely encoded genes [4], exhibiting highly conserved gene content and order, with most genes involved in major functions including photosynthesis, transcription, and translation $[5,6]$. Information provided by structural characteristics of chloroplast genomes can be helpful for inferring phylogenetic relationships among broad sets of plant taxa and enable studies on evolutionary forces that shape the plastome size and structure, such as gains and losses of genes and introns, expansion and contraction of the IRs, and inversion. Furthermore, analyzing the structure information of the chloroplast genome is of great significance for the study and utilization of chloroplast photosynthesis [7]. Furthermore, 
chloroplast genomes are predominantly featured by maternal inheritance, but in most conifers are inherited paternally, and transmitted in a biparental manner in a minority of angiosperm species, revealing clues of hybrid speciation [8-10]. In addition, the $\mathrm{cp}$ genome can be used in species delimitation and phylogenetic analysis, owing to its small genome size, less recombination, and uniparentally inheritance in most species, as well as its moderate nucleic acid replacement rate compared with the nuclear genome for most angiosperms [6]. However, in contrast to acquiring limited coverage of $\mathrm{cp}$ genomes for small samples by conventional DNA sequencing technology, such as Sanger sequencing, in recent years, continuous development of sequencing technology has provided massive sequencing reads from multiple samples simultaneously; moreover, the number of sequenced chloroplast genomes has increased rapidly with low cost.

The genus Salix L. (Salicaceae) is the largest genus of Salicaceae, with the number of species ranging from 450 to 520 , which can be divided into two categories according to their life forms: trees and shrubs [11-13]. Salix is widely distributed in the vast north temperate regions of Europe, Asia, and North America, and extends to tropical and subtropical alpine and Arctic regions [14]. Fast-growing shrub willows (Salix spp.) play an important role in the restoration of ecosystem habitats after disturbance and water and soil conservation, serving as important indicators of riparian habitats, and are also considered important energy crops $[15,16]$, thus, portraying the cp genome of shrub willow will help to improve energy production and fully exploit the production and application value of this economic species.

Salix spathulifolia Seemen, Salix cupularis Rehder, and Salix annulifera C.Marquand \& Airy Shaw (Salicaceae) are three shrubby willows endemic to western China, with the first two mainly distributed across Shaanxi, Gansu, Qinghai, northern Sichuan, and other provinces, and the latter mainly distributed across Yunnan and in the eastern Tibet, growing at high altitudes of more than 1800, 2500, and $3400 \mathrm{~m}$, respectively [12]. Morphologically, the three willow species show evolutionary characteristics of shrub lifeform and flowers with two stamens, which may be the characterization of an alpine group that gradually adapted to the alpine cold and arid environment [12,17-19]. However, because the genus Salix shows high intraspecies genotypic polymorphism and large phenotypic variation, it is difficult to determine the phylogenetic status of species [11,13]. Currently, the nuclear internal transcribed spacer (ITS) sequences and some plastid DNA sequences have been applied to study the phylogeny of Salix, which contain limited phylogenetic information [20-23]. Although Li et al. (2021) employed the complete chloroplast genomes to characterize the phylogenetic relationships of $S$. cupularis in the genus Salix, the authors chose Ginkgo bioloba L. as the outgroup rather than a more related species [24]. Moreover, research on these three willows is mainly focused on morphology and ecology [25], but their phylogenetic position and evolutionary relationship remain unclear.

Here, we report three complete chloroplast genomes of S. spathulifolia, S. cupularis, and S. annulifera, by analyzing the structure and sequence characteristics of $\mathrm{cp}$ genomes and comparing them to each other. Furthermore, the construction of a phylogenetic tree of chloroplast genomes of 21 Salix species could shed light on their evolutionary relationship.

\section{Materials and Methods}

\subsection{Plant Material}

The experimental materials of S. spathulifolia, S. cupularis, and S. annulifera were obtained from fresh leaves dried with silica gel in the western Chinese provinces of Shaanxi and Xizang at an altitude of at least $2400 \mathrm{~m}$. All the voucher specimens were deposited in the Herbarium of the Beijing Forestry University (Table 1).

\subsection{DNA Extraction and Genome Sequencing}

Whole-genomic DNA of all three species was extracted according to the CTAB method. After testing the quality of extracted DNA, a total amount of $1.5 \mu \mathrm{g}$ DNA per sample was used to construct a $150 \mathrm{bp}$ paired-end library, and the library was sequenced by the Illumina 
HiSeq4000 platform with an insert size of around $350 \mathrm{bp}$ at Shanghai Majorbio Bio-pharm Technology Co., Ltd, Shanghai, China. The raw data after sequencing the chloroplast genomes of three willows were taken from Gulyaev et al. in preparing [26]. In order to ensure the quality of subsequent analysis, we used Fastp with default settings to remove low-quality sequences and adapters from the raw data [27]. We deposited the samples of the complete chloroplast genome sequences to the NCBI GenBank (accessions MZ365445, MZ365446, MZ365447).

Table 1. Basic information on the sampling sites of the studied willow species.

\begin{tabular}{ccccccc}
\hline Species & Collecting Number & Longitude & Latitude & Altitude & Province & Herbaria \\
\hline Salix & HLCS19_15 & $108.80^{\circ} \mathrm{E}$ & $33.86^{\circ} \mathrm{N}$ & $2456 \mathrm{~m}$ & Shaanxi & BJFC \\
spathulifolia & HLCS19_45 & $107.81^{\circ} \mathrm{E}$ & $34.00^{\circ} \mathrm{N}$ & $3377 \mathrm{~m}$ & Shaanxi & BJFC \\
Salix cupularis & ZZX2019091207 & $94.97^{\circ} \mathrm{E}$ & $29.47^{\circ} \mathrm{N}$ & $3559 \mathrm{~m}$ & Tibet & BJFC \\
\hline
\end{tabular}

\subsection{Chloroplast Genome Assembly and Annotation}

We used Geneious 10.2 to conduct the entire chloroplast genome assembly process [28], mainly following He et al. [29]. Low-quality sequencing bases at both ends were clipped out with an error probability limit of 0.05 . Then, the Map to Reference function was used to map filtered reads which excludes nuclear and mitochondrial reads to published plastid genomes of S. babylonica L. (MF189167) [30], S. chaenomeloides Kimura (MG262362), S. rehderiana C.K.Schneid. (MG262367), S. rorida (MG262368), and S. taoensis Goerz ex Rehder \& Kobuski (MG262369), which were set as references (iterate up to 10 times). The subsequent chloroplast reads were used for de novo assembly of the contigs with a mediumlow sensitivity setting. Usually, there is only one contig (approximately $130 \mathrm{~kb}$ ) that results from de novo assembly. The filtered reads were repeatedly mapped to the contigs to increase length; if more than one smaller contig was obtained, overlapping regions were used to enable all the contigs to be concatenated to a $130 \mathrm{~kb}$ contig with four junctions between two single-copy and IRs regions being confirmed. The Find Repeats Plug-in function was used to define the IR regions, which were copied and inverted manually to construct complete chloroplast genome sequences.

Plastid Genome Annotator (PGA) was used to perform initial annotations of complete chloroplast genome [31] with Salix suchowensis [32] as a reference and manually corrected with Plann 1.1.2 [33] and Geneious [28]. Finally, the circular graphical map of the $c p$ genomes was drawn by the OGDRAW online tool [34].

\subsection{Repeat Sequence and Codon Usage Analysis}

We applied MISA-web to predict repeat sequences of chloroplast microsatellites (cpSSRs) [35] with parameters set to: minimum number of eight repeated motifs for mononucleotide, five repeated motifs for dinucleotide, four repeated motifs for trinucleotide, and three repeated motifs for tetra- and pentanucleotide repeats. Online REPuter software was employed to discover interspersed repeats in whole cp genomes, which included forward, reverse, complement, and palindromic repeats [36] with a minimum repeat size of $30 \mathrm{bp}$ and the Hamming distance set to three. We used Geneious 10.2 [28] to calculate the percent of guanine-cytosine (GC). The relative synonymous codon usage (RSCU) determining the preference for the use of a codon was generated using MEGA 7 [37] based on 85 protein-coding genes (PCG) sequences. An RSCU not greater than 1.0 means no preference, while an RSCU greater than 1 means preference.

\subsection{Genome Comparison and Sequence Divergence}

Three willow cp genomes were globally compared with the Shuffle-LAGAN mode in online mVISTA software with default settings [38] by employing the S. spathulifolia as an annotation reference. Moreover, we conducted a DNA polymorphism analysis to detect nucleotide diversity $(\pi)$ with a $100 \mathrm{bp}$ window size and a $25 \mathrm{bp}$ step size by using DnaSP 
version 6 [39]. IRscope online [40] was used to analyze and visualize the borders between LSC/IRs and SSC/IRs among the three willow cp genomes.

\subsection{Phylogenetic Research}

The maximum likelihood (ML) phylogeny was applied to investigate the phylogenetic status of S. spathulifolia, S. annulifera, and S. cupularis. The cp genome sequences of 18 Salix and two Populus species were obtained from the NCBI genome database (National Center for Biotechnology Information). After manually checking the region direction, a total of $20 \mathrm{cp}$ genomes along with three target willows were ultimately aligned using MAFFT online version [41] and then by Phylosuite V1.2.2 [42]. The ML tree was estimated using the best nucleotide replacement model GTR + F + I estimated by ModelFinder [43] implemented in Phylosuite [42]. The two Populus species were set as outgroups. We used bootstrap replicates of 5000 to test the confidence of each branch.

\section{Results and Discussion}

\subsection{Genome Features}

Full-length complete cp genomes of the three Salix species were accomplished varying from 155,566 to $155,680 \mathrm{bp}$ and the genome structure comprised two IR regions (range from 27,453 to $27,461 \mathrm{bp}$ ), separated by an LSC region (84,431-84,552 bp) and an SSC region $(16,206-16,221 \mathrm{bp})$ (Figure 1, Table 2). The overall GC content for all three willow species was about $36.7 \%$, while IR regions displayed a higher GC content $(41.9 \%)$ than the GC content of LSC (34.4\%) and SSC (31.0\%). This GC content distribution pattern seemed to be common in other plants [44], which is caused by a relatively high GC content in rRNA and tRNA genes [45], occupying more area than that of protein-coding genes in IR regions.

Table 2. Summary of chloroplast genome features of S. spathulifolia, S. cupularis, and S. annulifera.

\begin{tabular}{|c|c|c|c|c|}
\hline & & S. spathulifolia & S. cupularis & S. annulifera \\
\hline Accession Number & & HLCS19_15 & HLCS19_45 & ZZX2019091207 \\
\hline \multirow{2}{*}{ Genome } & Length (bp) & 155,680 & 155,566 & 155,626 \\
\hline & GC $(\%)$ & 36.7 & 36.7 & 36.7 \\
\hline \multirow{3}{*}{ LSC } & Length (bp) & 84,552 & 84,431 & 84,499 \\
\hline & GC $(\%)$ & 34.4 & 34.4 & 34.4 \\
\hline & Length (\%) & 54.31 & 54.27 & 54.30 \\
\hline \multirow{3}{*}{ SSC } & Length (bp) & 16,206 & 16,217 & 16,221 \\
\hline & GC $(\%)$ & 31.0 & 31.0 & 30.9 \\
\hline & Length $(\%)$ & 10.41 & 10.42 & 10.42 \\
\hline \multirow{3}{*}{ IR } & Length (bp) & 27,461 & 27,459 & 27,453 \\
\hline & GC $(\%)$ & 41.9 & 41.9 & 41.9 \\
\hline & Length $(\%)$ & 17.64 & 17.65 & 17.64 \\
\hline \multirow{5}{*}{$\begin{array}{l}\text { No. of genes } \\
\text { (duplicated in IR) }\end{array}$} & Genes & $130(19)$ & $130(20)$ & $130(21)$ \\
\hline & PCGs & $85(8)$ & $85(9)$ & $85(10)$ \\
\hline & tRNA & $37(7)$ & $37(8)$ & $37(9)$ \\
\hline & rRNA & $8(4)$ & $8(5)$ & $8(6)$ \\
\hline & With introns & $17(5)$ & $17(6)$ & $17(7)$ \\
\hline
\end{tabular}




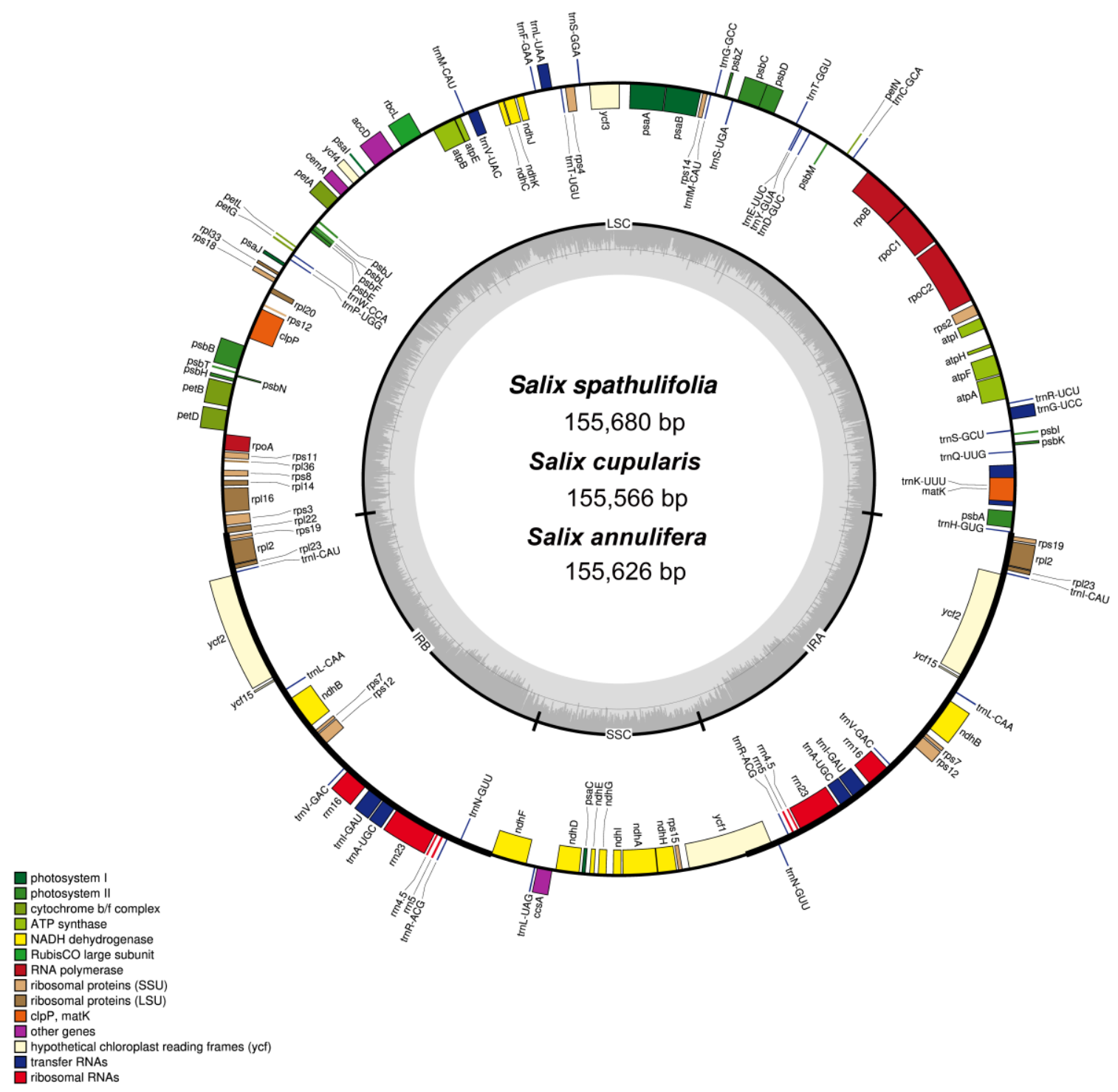

Figure 1. Circular map of cp genomes S. spathulifolia, S. cupularis, and S. annulifera. Genes transcribed clockwise are drawn outside the circle, while those transcribed counterclockwise are drawn inside. Genes are encoded in diversified colors according to their different functional groups. GC content of the chloroplast genome of Salix spathulifolia is represented by grey area in the inner circle.

In each of the three cp genomes, 130 genes were predicted (85 protein-coding genes, 37 tRNAs, and 8 rRNAs), of which 19, 20, and 21 genes were duplicated in IR regions, respectively (Table 2). Seventeen genes containing introns were identified, which was the same as in the previous study [30].

According to the genes' functions, they can be divided into 17 groups, of which 57 genes were found to be related to self-replication: 11, 8, 4, 4, 30 genes were responsible for encoding small ribosomal subunit protein, large ribosomal subunit protein, and RNA polymerase subunits, rRNAs, and tRNAs respectively. Another category contained 46 genes related to photosynthesis, involving 7 photosystem I genes, 15 photosystem II genes, 6 cytochrome $\mathrm{b} / \mathrm{f}$ complex genes, 6 ATP synthase genes, $11 \mathrm{ndh}$ genes, and 1 large subunit Rubisco gene (Table 3). 
Table 3. Gene composition in the chloroplast genomes of S. spathulifolia, S. cupularis, and S. annulifera.

\begin{tabular}{|c|c|}
\hline Groups of Genes & Name of Genes \\
\hline Transfer RNAs & 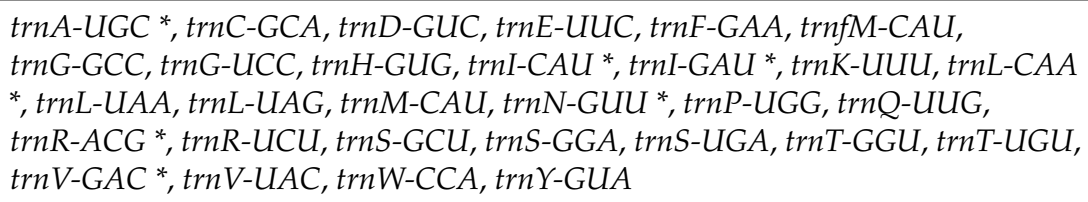 \\
\hline Ribosomal RNAs & $r r n 4.5^{*}, r r n 5^{*}, r r n 16^{*}, r r n 23 *$ \\
\hline Ribosomal protein small subunit & rps $2, r p s 3, r p s 4, r p s 7^{*}, r p s 8, r p s 11, r p s 12 *, r p s 14, r p s 15, r p s 18, r p s 19 *$ \\
\hline Ribosomal protein large subunit & rpl2 $*$, rpl14, rpl16, rpl20, rpl22, rpl23*, rpl33, rpl36 \\
\hline Subunits of RNA polymerase & rро $A$, гров, гроС1, гроС2 \\
\hline Photosystem I & $p s a A, p s a B, p s a C, p s a I, p s a J, y c f 3, y c f 4$ \\
\hline Photosystem II & $\begin{array}{l}p s b A, p s b B, p s b C, p s b D, p s b E, p s b F, p s b H, p s b I, p s b J, p s b K, p s b L, p s b M, p s b N, p s b T \text {, } \\
p s b Z\end{array}$ \\
\hline Cytochrome b/f complex & $\operatorname{pet} A, \operatorname{pet} B, \operatorname{pet} D, \operatorname{pet} G, \operatorname{pet} L, \operatorname{pet} N$ \\
\hline ATP synthase & $\operatorname{atp} A, \operatorname{atpB}, \operatorname{atpE}, \operatorname{atpF}, \operatorname{atpH}$, atpI \\
\hline NDH complex & $n d h A, n d h B *, n d h C, n d h D, n d h E, n d h F, n d h G, n d h H, n d h I, n d h J, n d h K$ \\
\hline Large subunit Rubisco & $r b c L$ \\
\hline Acetyl-CoA carboxylase & $a c c D$ \\
\hline Maturase & matK \\
\hline Inner membrane protein & $\operatorname{cem} A$ \\
\hline ATP-dependent protease & $\operatorname{clpP}$ \\
\hline Cytochrome c biogenesis & $\operatorname{ccs} A$ \\
\hline Conserved open reading frames & $y c f 1, y c f 2 *, y c f 15 *$ \\
\hline
\end{tabular}

Note: "*" means duplicated genes.

Seventeen genes contained introns, six of them were tRNA and the remaining encoded proteins. Among these intron-containing genes, 14 out of 17 included a single intron and 3 genes $(y c f 3, c l p P$, and rps12) had two introns (Table 4). In comparison with other introns, the longest intron was within the trnK-UUU gene in the LSC region, where the matK gene was located, reaching $2547 \mathrm{bp}$. By contrast, the intron of the $t r n L-U A A$ gene was the shortest, only $586 \mathrm{bp}$. The same as most species [46-48], the rps12 gene was trans-spliced, which encoded the $40 S$ ribosomal protein S12 because one exon in the $5^{\prime}$-end is located in the LSC region and the other two exons in the $3^{\prime}$-end are located in both IR regions. No pseudogenes were found because no stop codons were found in coding sequences.

Table 4. Characteristics of intron-containing genes in the chloroplast genome of S. spathulifolia.

\begin{tabular}{|c|c|c|c|c|c|c|}
\hline Gene & Location & Exon I (bp) & Intron I (bp) & Exon II (bp) & Intron II (bp) & Extron III (bp) \\
\hline trnK-UUU & LSC & 37 & 2547 & 35 & & \\
\hline rpl16 & LSC & 9 & 1120 & 399 & & \\
\hline $\operatorname{trn} G-U C C$ & LSC & 23 & 693 & 48 & & \\
\hline atpF & LSC & 145 & 741 & 398 & & \\
\hline rpoC1 & LSC & 453 & 777 & 1617 & & \\
\hline$y c f 3$ & LSC & 126 & 723 & 228 & 667 & 153 \\
\hline $\operatorname{trnL-UAA}$ & LSC & 35 & 586 & 50 & & \\
\hline $\operatorname{trn} V-U A C$ & LSC & 39 & 609 & 35 & & \\
\hline$c l p P$ & LSC & 71 & 837 & 292 & 585 & 228 \\
\hline petB & LSC & 6 & 811 & 642 & & \\
\hline petD & LSC & 8 & 788 & 490 & & \\
\hline$n d h A$ & SSC & 552 & 1107 & 546 & & \\
\hline$r p l 2$ & IR & 397 & 668 & 434 & & \\
\hline rps12 & LSC\&IR & 114 & $\sim$ & 232 & 536 & 26 \\
\hline$n d h B$ & IR & 723 & 682 & 756 & & \\
\hline $\operatorname{trnI-GAU}$ & IR & 37 & 949 & 35 & & \\
\hline $\operatorname{trn} A-U G C$ & IR & 38 & 802 & 35 & & \\
\hline
\end{tabular}


Features of the S. cupularis, S. annulifera, and S. spathulifolia chloroplast genomes were compared and the results showed that the cp genomes of S. cupularis and S. annulifera were 114 and $54 \mathrm{bp}$ shorter than that of S. spathulifolia, respectively. Compared with S. spathulifolia, the LSC and IR region lengths of S. cupularis and S. annulifera were shorter, while the SSC region lengths were 11 and 15 bp longer. Furthermore, the whole genome GC content among the three willow species was almost the same, and the difference in GC content only exists in the SSC region. Moreover, there was no variation in gene content and order among the three willow species, including intron-containing genes.

\subsection{Codon Usage and Repeat Sequence Analysis}

A total of 26,115, 26,131, and 26,138 codons were identified in the cp genomes of S. cupularis, S. annulifera, and S. spathulifolia, respectively. The number of codons encoding leucine was the largest and the least abundant were those for cysteine, which was the same as for the other two species. Across the three genomes, there were 30 preferred synonymous codons (RSCU > 1); except for the UUG codon ending with G, the others ended with A or U. Moreover, the use of the two codons AUG and UGG had no preference for codon usage (RSCU = 1) (Table 5).

Table 5. RSCU in S. spathulifolia, S. cupularis, and S. annulifera chloroplast genomes.

\begin{tabular}{|c|c|c|c|c|c|c|c|}
\hline \multirow{2}{*}{ Codon } & \multirow{2}{*}{ Amino Acid } & \multicolumn{2}{|c|}{ S. spathulifolia } & \multicolumn{2}{|c|}{ S. cupularis } & \multicolumn{2}{|c|}{ S. annulifera } \\
\hline & & Count & RSCU & Count & RSCU & Count & RSCU \\
\hline UUU & Phe & 987 & 1.31 & 988 & 1.31 & 992 & 1.31 \\
\hline UUC & Phe & 516 & 0.69 & 517 & 0.69 & 517 & 0.69 \\
\hline UUA & Leu & 892 & 1.91 & 894 & 1.91 & 894 & 1.91 \\
\hline UUG & Leu & 569 & 1.22 & 570 & 1.22 & 570 & 1.22 \\
\hline CUU & Leu & 586 & 1.25 & 586 & 1.25 & 586 & 1.25 \\
\hline CUC & Leu & 178 & 0.38 & 180 & 0.38 & 179 & 0.38 \\
\hline CUA & Leu & 398 & 0.85 & 397 & 0.85 & 397 & 0.85 \\
\hline CUG & Leu & 179 & 0.38 & 179 & 0.38 & 180 & 0.38 \\
\hline AUU & Ile & 1127 & 1.49 & 1129 & 1.49 & 1130 & 1.49 \\
\hline AUC & Ile & 432 & 0.57 & 432 & 0.57 & 430 & 0.57 \\
\hline AUA & Ile & 708 & 0.94 & 708 & 0.94 & 711 & 0.94 \\
\hline AUG & Met & 620 & 1 & 621 & 1 & 621 & 1 \\
\hline GUU & Val & 493 & 1.42 & 492 & 1.42 & 491 & 1.41 \\
\hline GUC & Val & 167 & 0.48 & 167 & 0.48 & 167 & 0.48 \\
\hline GUA & Val & 532 & 1.53 & 532 & 1.53 & 533 & 1.53 \\
\hline GUG & Val & 199 & 0.57 & 199 & 0.57 & 199 & 0.57 \\
\hline UCU & Ser & 572 & 1.69 & 573 & 1.69 & 573 & 1.69 \\
\hline UCC & Ser & 332 & 0.98 & 329 & 0.97 & 329 & 0.97 \\
\hline UCA & Ser & 409 & 1.21 & 408 & 1.2 & 409 & 1.21 \\
\hline UCG & Ser & 184 & 0.54 & 186 & 0.55 & 185 & 0.55 \\
\hline $\mathrm{CCU}$ & Pro & 418 & 1.56 & 418 & 1.57 & 420 & 1.57 \\
\hline $\mathrm{CCC}$ & Pro & 198 & 0.74 & 197 & 0.74 & 199 & 0.74 \\
\hline CCA & Pro & 308 & 1.15 & 306 & 1.15 & 308 & 1.15 \\
\hline CCG & Pro & 145 & 0.54 & 145 & 0.54 & 143 & 0.53 \\
\hline $\mathrm{ACU}$ & Thr & 522 & 1.6 & 524 & 1.6 & 524 & 1.6 \\
\hline $\mathrm{ACC}$ & Thr & 238 & 0.73 & 236 & 0.72 & 238 & 0.73 \\
\hline ACA & Thr & 423 & 1.29 & 424 & 1.29 & 423 & 1.29 \\
\hline $\mathrm{ACG}$ & Thr & 126 & 0.39 & 126 & 0.38 & 124 & 0.38 \\
\hline GCU & Ala & 620 & 1.83 & 620 & 1.83 & 620 & 1.83 \\
\hline GCC & Ala & 202 & 0.6 & 205 & 0.61 & 204 & 0.6 \\
\hline GCA & Ala & 385 & 1.14 & 385 & 1.14 & 385 & 1.14 \\
\hline GCG & Ala & 145 & 0.43 & 143 & 0.42 & 145 & 0.43 \\
\hline UAU & Tyr & 777 & 1.64 & 780 & 1.65 & 780 & 1.64 \\
\hline UAC & Tyr & 171 & 0.36 & 168 & 0.35 & 170 & 0.36 \\
\hline
\end{tabular}


Table 5. Cont.

\begin{tabular}{|c|c|c|c|c|c|c|c|}
\hline \multirow{2}{*}{ Codon } & \multirow{2}{*}{ Amino Acid } & \multicolumn{2}{|c|}{ S. spathulifolia } & \multicolumn{2}{|c|}{ S. cupularis } & \multicolumn{2}{|c|}{ S. annulifera } \\
\hline & & Count & RSCU & Count & RSCU & Count & RSCU \\
\hline UAA & * & 45 & 1.59 & 45 & 1.59 & 45 & 1.59 \\
\hline UAG & * & 22 & 0.78 & 22 & 0.78 & 22 & 0.78 \\
\hline CAU & His & 477 & 1.52 & 478 & 1.52 & 477 & 1.52 \\
\hline CAC & His & 150 & 0.48 & 150 & 0.48 & 149 & 0.48 \\
\hline CAA & Gln & 713 & 1.55 & 715 & 1.55 & 716 & 1.55 \\
\hline CAG & Gln & 209 & 0.45 & 209 & 0.45 & 209 & 0.45 \\
\hline AAU & Asn & 978 & 1.53 & 981 & 1.53 & 981 & 1.53 \\
\hline $\mathrm{AAC}$ & Asn & 300 & 0.47 & 300 & 0.47 & 299 & 0.47 \\
\hline AAA & Lys & 1051 & 1.47 & 1052 & 1.47 & 1050 & 1.47 \\
\hline AAG & Lys & 376 & 0.53 & 376 & 0.53 & 375 & 0.53 \\
\hline GAU & Asp & 833 & 1.58 & 832 & 1.58 & 834 & 1.58 \\
\hline GAC & Asp & 223 & 0.42 & 223 & 0.42 & 222 & 0.42 \\
\hline GAA & Glu & 1023 & 1.49 & 1022 & 1.49 & 1023 & 1.49 \\
\hline GAG & Glu & 347 & 0.51 & 347 & 0.51 & 346 & 0.51 \\
\hline UGU & Cys & 213 & 1.42 & 212 & 1.42 & 213 & 1.42 \\
\hline UGC & Cys & 86 & 0.58 & 87 & 0.58 & 86 & 0.58 \\
\hline UGA & $*$ & 18 & 0.64 & 18 & 0.64 & 18 & 0.64 \\
\hline UGG & $\operatorname{Trp}$ & 452 & 1 & 452 & 1 & 453 & 1 \\
\hline CGU & Arg & 328 & 1.28 & 330 & 1.29 & 330 & 1.29 \\
\hline CGC & Arg & 109 & 0.43 & 108 & 0.42 & 109 & 0.43 \\
\hline CGA & Arg & 357 & 1.4 & 361 & 1.41 & 358 & 1.4 \\
\hline CGG & Arg & 106 & 0.42 & 104 & 0.41 & 105 & 0.41 \\
\hline AGU & Ser & 408 & 1.2 & 408 & 1.2 & 407 & 1.2 \\
\hline AGC & Ser & 128 & 0.38 & 128 & 0.38 & 128 & 0.38 \\
\hline AGA & Arg & 471 & 1.84 & 471 & 1.84 & 473 & 1.85 \\
\hline AGG & Arg & 161 & 0.63 & 161 & 0.63 & 161 & 0.63 \\
\hline GGU & Gly & 556 & 1.25 & 556 & 1.25 & 557 & 1.26 \\
\hline GGC & Gly & 192 & 0.43 & 192 & 0.43 & 192 & 0.43 \\
\hline GGA & Gly & 711 & 1.6 & 711 & 1.6 & 709 & 1.6 \\
\hline GGG & Gly & 314 & 0.71 & 316 & 0.71 & 315 & 0.71 \\
\hline
\end{tabular}

Note: “*” means terminal codons.

Using MISA-web, we detected 222 SSRs in the three cp genomes, of which the most were mono- and tetra-nucleotide types. In S. spathulifolia, the most abundant SSR type was mononucleotide repeats, with a total number of 197, followed by tetranucleotide (12), dinucleotide (10), and the least abundant were trinucleotide (1), pentanucleotide (1), and hexanucleotide (1) (Table S1 and Figure 2a). The numbers of mononucleotides in S. cupularis and S. annulifera were 199 and 196, respectively; however, the numbers of trinucleotide and pentanucleotide repeats were identical. Variations in the dinucleotide, tetranucleotide, and hexanucleotide repeats were no more than one. No hexanucleotide repeats were identified in the $\mathrm{S}$. cupularis $\mathrm{cp}$ genome. In terms of base composition, among the three cp genomes, the most common type of SSRs was A/T type mononucleotide, accounting for $82.88-84.23 \%$ (Figure $2 \mathrm{~b}$ ). The longest SSR had a length of $18 \mathrm{bp}$ while the shortest was $8 \mathrm{bp}$ (Table S1). Comparison among the three willows showed high similarity in SSR type and quantity. 


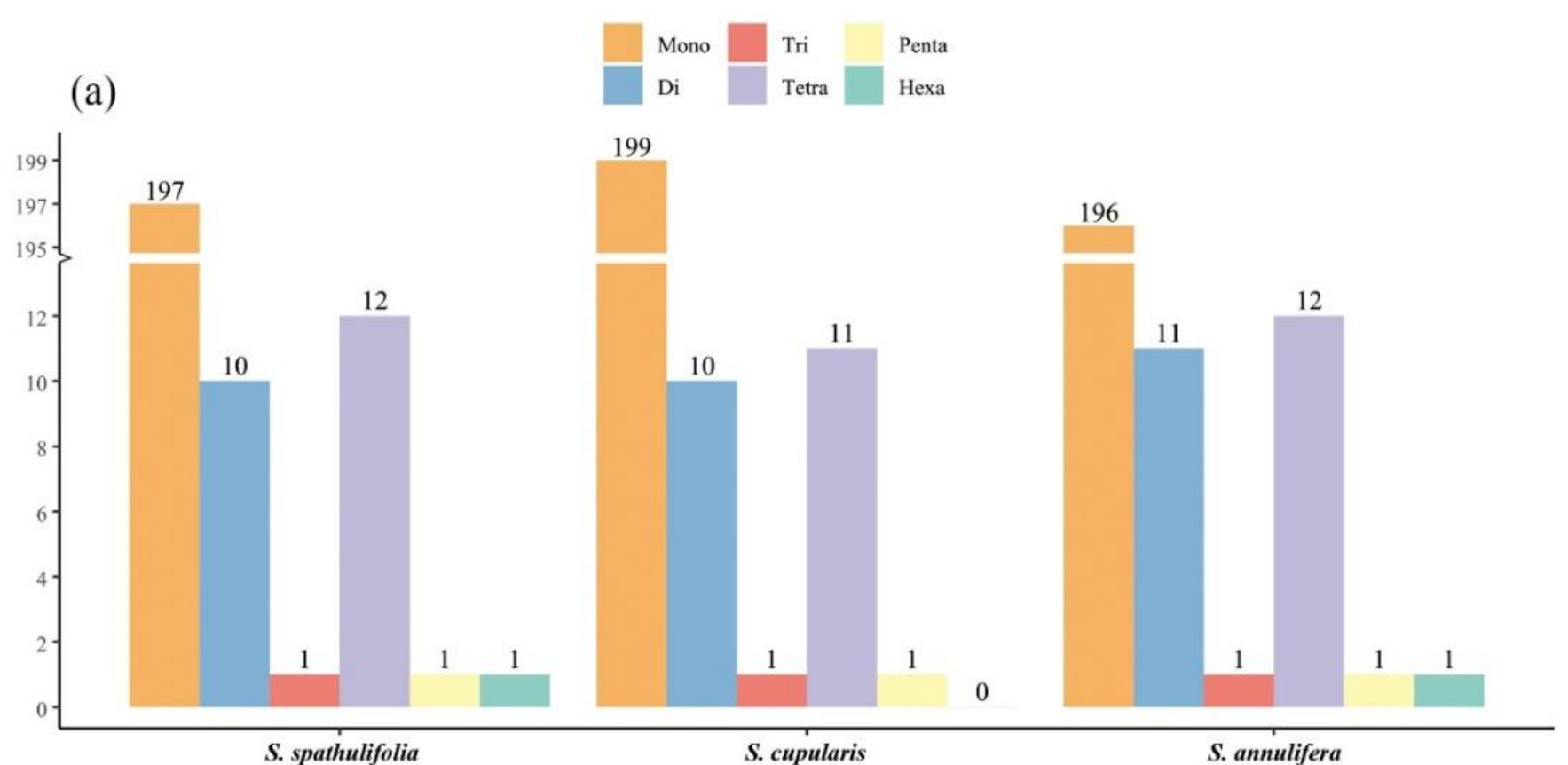

(b)

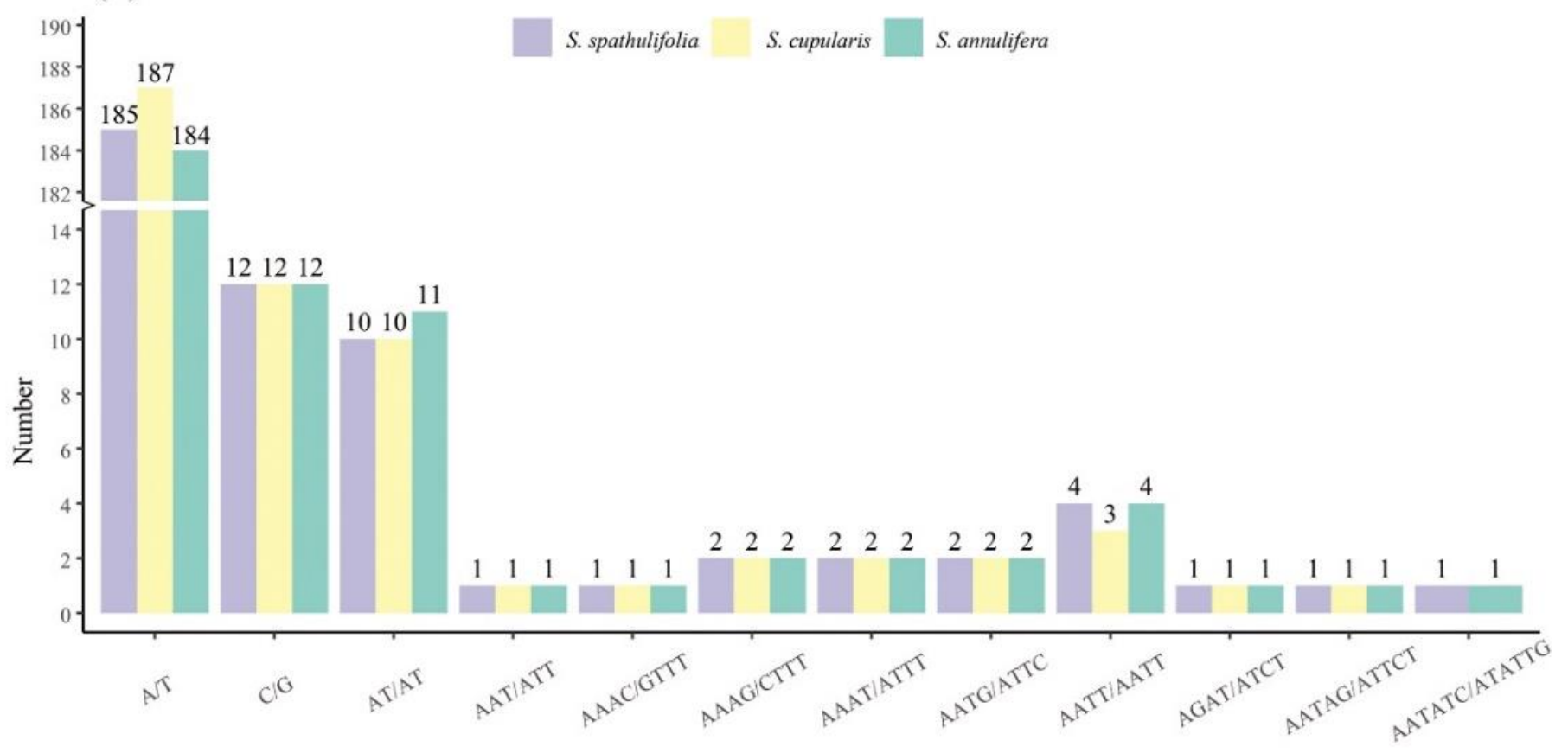

Figure 2. Simple sequence repeats (SSRs) in the chloroplast genomes of S. spathulifolia, S. cupularis, and S. annulifera. (a) Number of each repeat type; (b) type and number of SSR loci.

Based on the REPuter result, S. spathulifolia had the most repeats (46): 25 forward, 14 palindromic, 4 reverse, and 3 complement (Figure 3 ). The repetitive sequences ranged in size from 30 to $76 \mathrm{bp}$ with a Hamming distance of 3 . The most abundant repeats identified in the cp genome were $30 \mathrm{bp}$ (12 sites) followed by 32 bp (10 sites) (Table S2). Comparatively, S. annulifera had the smallest number of repeats both in total (34) and in each group (21 forward, 11 palindromic, 1 reverse, 1 complement). The four repeat types were rankorder arranged according to the number of repeats of each type in three willows: Forward (F)—most; Palindromic (P)—second; Reverse (R)—-third; and Complement (C)—least. In addition, no complement repeats were found in the cp genome of $\mathrm{S}$. cupularis. 


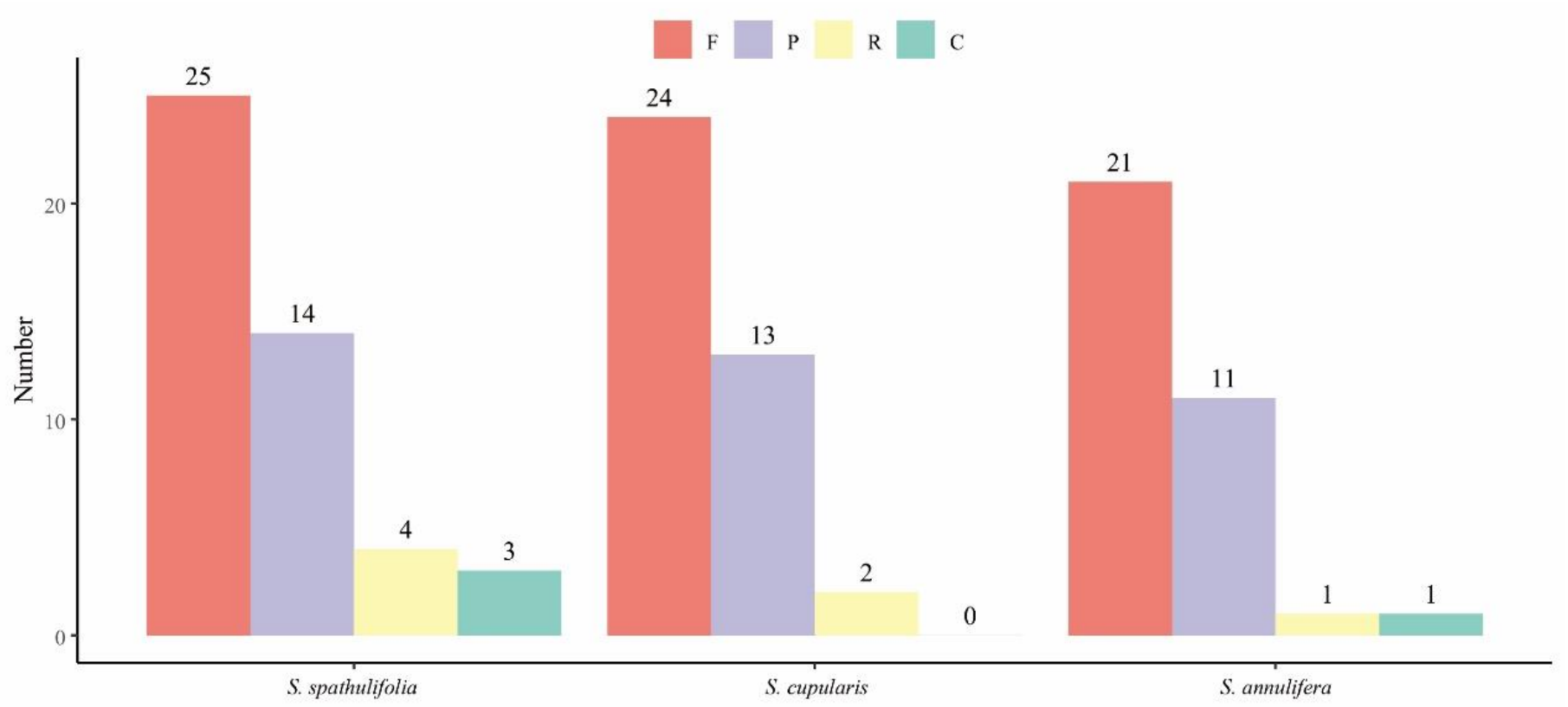

Figure 3. Number of repeats detected in the chloroplast genomes of S. spathulifolia, S. cupularis, and S. annulifera. (F: Forward; R: Reverse; C: Complement; and P: Palindromic).

\subsection{Genome Comparison}

The chloroplast genomes of the three Salix taxa were compared and analyzed using mVISTA online software with S. spathulifolia as a reference. Overall, the comparative genomic analysis showed that the three willows' cp genome sequences were relatively conserved. Generally, higher variation was found in non-coding regions. The most divergent regions in the coding sequences were $p s b L, r p l 16$, and $y c f 1$. The regions with relatively higher variation were mainly concentrated in the LSC and SSC regions; however, the IR regions were more conserved (Figure 4). Similar results can be revealed by a sliding window analysis, which determines the nucleotide diversity in chloroplasts. The average $\mathrm{Pi}$ of the three chloroplast genomes was 0.00075 , and high nucleotide variability $(\pi)$ was exhibited at the SC regions in comparison to IR regions (Figure 5). Due to the difficulty in resolving the phylogeny of the genus Salix, these divergent regions-with the highest variation in Salix cp genomes-can be identified as a source of potential molecular markers.

The four junctions in the three willows' cp genomes were presented using IRscope (Figure 6). Overall, the distribution of genes on each border was almost identical, with only slight differences among the three willows. The LSC/IRb border was inside the rpl22 gene in all three willows. The $347 \mathrm{bp}$ fragment of the rpl22 is located within the LSC region, whereas the remaining $52 \mathrm{bp}$ section of this gene can be found within the $\mathrm{IRb}$ region. The IRb/SSC boundary is located inside the $n d h F$ gene. The $10 \mathrm{bp}$ fragment of the $n d h F$ gene is located within the IRb region, whereas the remaining $2264 \mathrm{bp}$ section of this gene can be found within the SSC region. The ycf1 gene is located across the SSC/IRa junction. Compared to S. annulifera, the parts of the ycf1 gene in the SSC of S. cupularis and S. spathulifolia were $6 \mathrm{bp}$ shorter, whereas the parts of the ycf1 gene in the IRa region were the same (1748 bp). The rps19 gene was fully located in the IRa, while the trnH gene was fully located in the LSC, 1 bp away from the IRa/LSC border. 

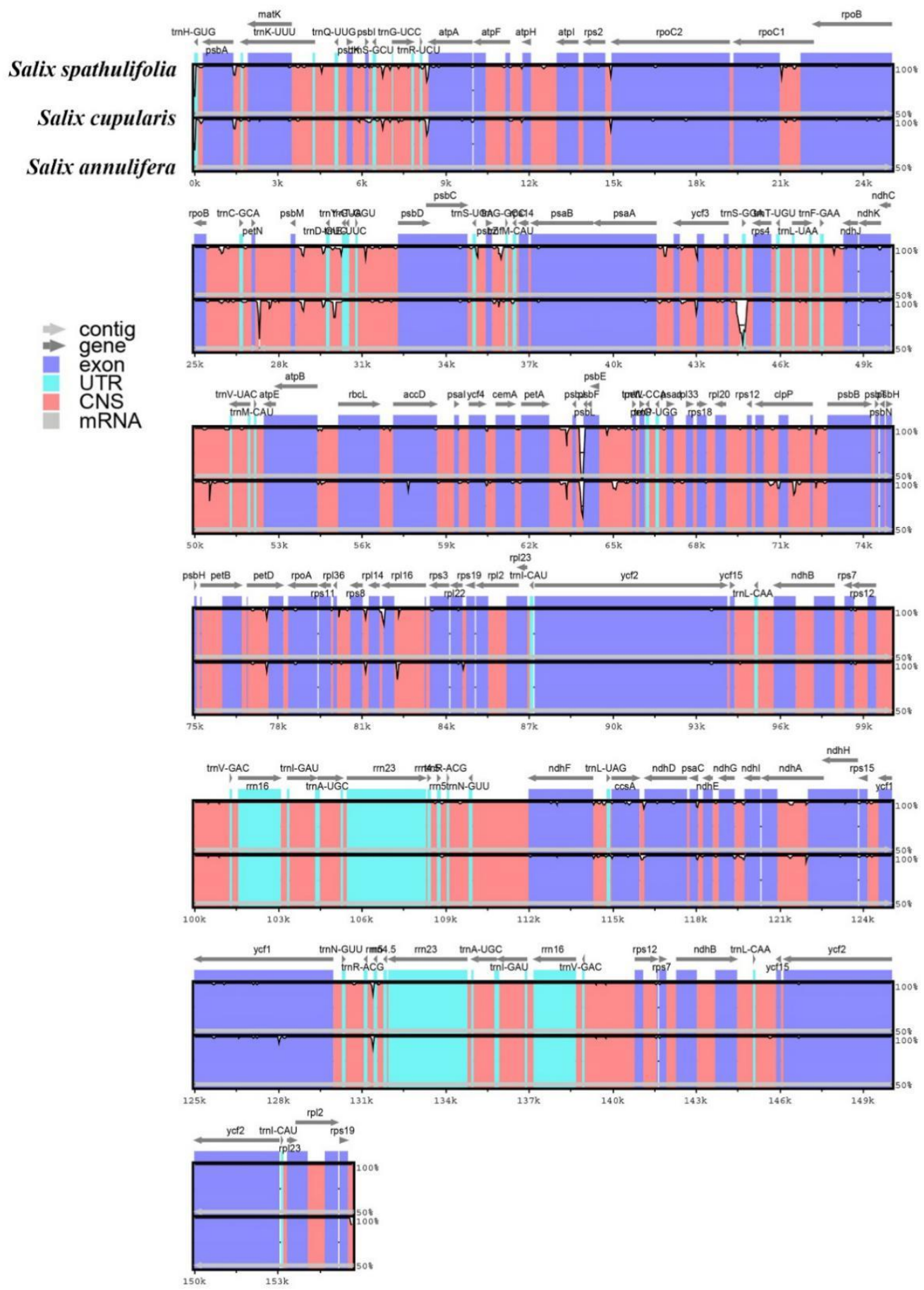

Figure 4. Sequence alignment of the three complete chloroplast genomes generated by mVISTA, with S. spathulifolia as reference. The $x$-axis represents the sequence length and the $y$-axis indicates the identity from 50 to $100 \%$. Arrows indicate annotated genes and the direction of their transcription. UTR: untranslated regions; CNS: conserved non-coding sequences. 


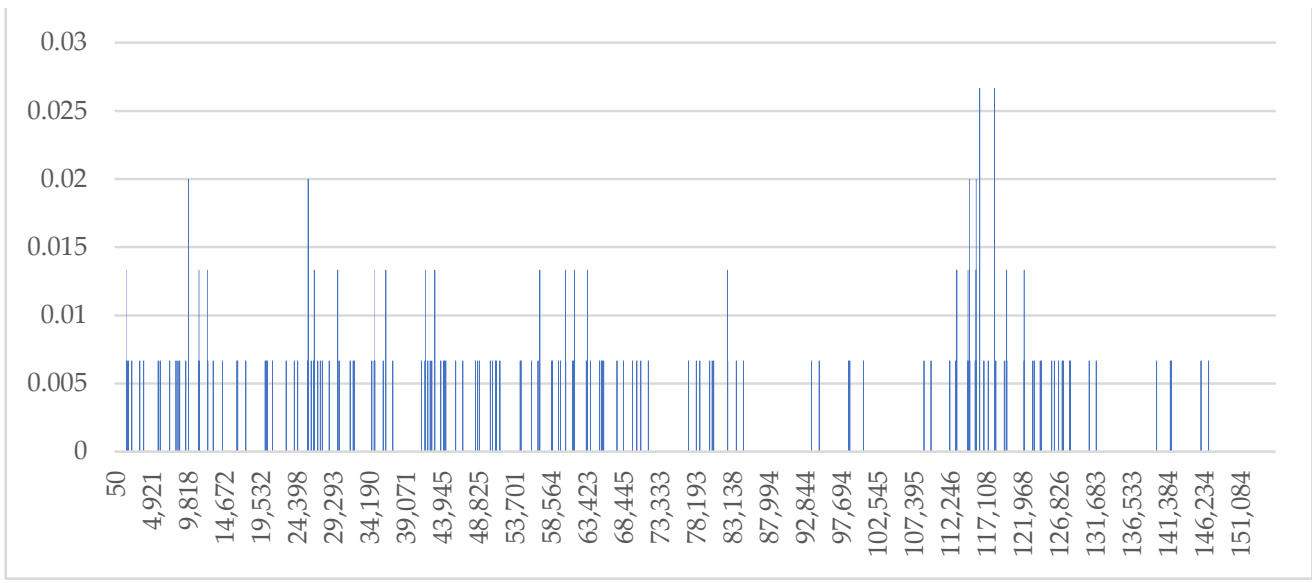

Figure 5. Sliding window analysis of the three willows whole plastid genomes ( $X$-axis, position of the midpoint of a window; $Y$-axis, nucleotide diversity of each window).

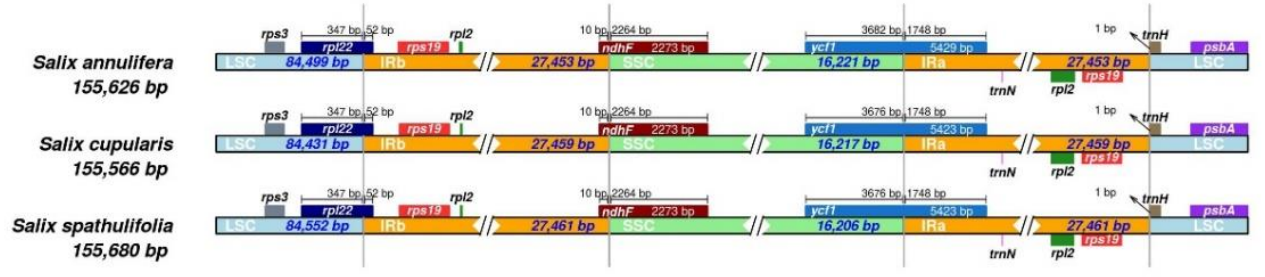

Figure 6. Comparison of the LSC, SSC, and IRs boundary regions among three Salix chloroplast genomes.

\subsection{Phylogenetic Analysis}

To explore the phylogenetic status of these three willows, an ML phylogeny was built using the complete cp genomes of 20 Salicaceae species published on NCBI and three in our study (Figure 7). As shown in Figure 7, all the available willows were evidently divided into two major groups, consistent with a previous study [49]. The three target willows were all in clade I. S. spathulifolia was at the base of clade I; S. annulifera was most closely to $S$. rorida, while $S$. cupularis was resolved as a separate branch and placed as a sister group to S. suchowensis and S. psammophila, which belonged to sect. Helix. The phylogenetic tree generated a total of 21 nodes, and bootstrap support was $100 \%$ in 11 out of 21 branch nodes.

However, in Li et al. (2021) the phylogenetic placement of Salix cupularis contradicted our result, which may be related to some reasons about constructing phylogenetic tree and origin of samples. Firstly, outgroup sampling was a crucial step in phylogenetic analyses, affecting homoplasy between ingroup and the outgroup and statistical error rate, thus, an outgroup with large genetic distance from the ingroup may share few relevant character states and took a long time to accumulate homoplasy, attach randomly to the ingroup, and bias ingroup relationships, and this was the reason why we selected genus Populus, the sister group of Salix to root the phylogenetic tree [50-52]. Meanwhile, methods of tree construction may have an effect on the phylogenetic results. The reconstruction methods of phylogeny can be divided into two categories: distance-based and sequence-based. The most popular distance method was the NJ method, which used the distance matrix as input to specify the distance between each pair of taxa, however, different from the NJ method, ML method was based on a clear sequence evolution model and likelihood function, one of the advantages of the ML method was that all its model assumptions are clear, so they can be evaluated and improved, generally speaking, if the model was appropriate, ML method outperformed other methods [53]. Furthermore, considering the considerable intraspecific genotypical polymorphisms, extensive interspecific hybridization, and chloroplast capture 
result from reduced sterility barriers among taxa, establishing phylogeny of the genus Salix was difficult [54]. Our sample was taken from the vicinity of the type locality, which was some distance from the sampling sites mentioned in Li et al. [24]. We inferred that this may also be one of the reasons for the inconsistent phylogenetic results.

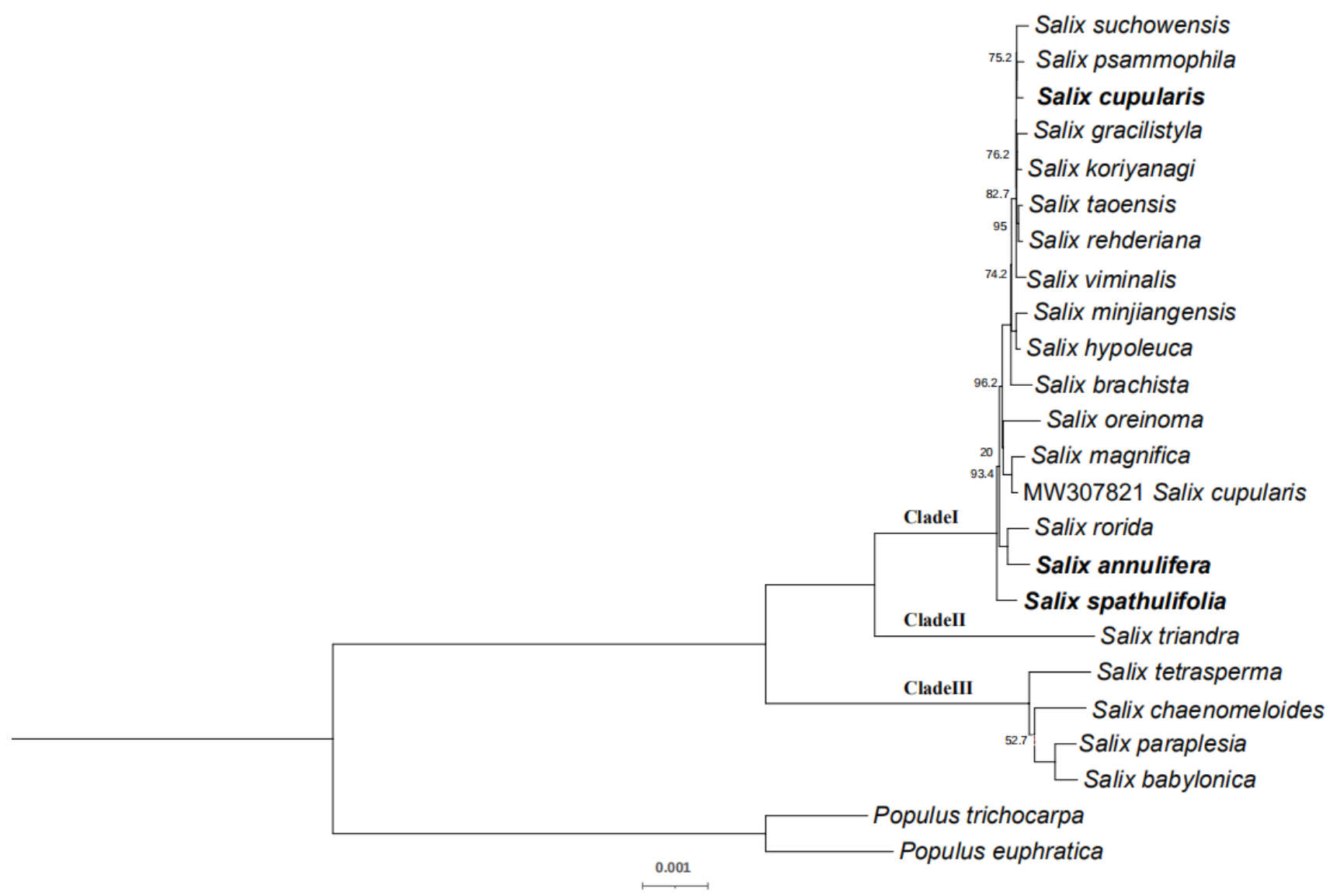

Figure 7. Maximum likelihood (ML) phylogeny of 23 species belonging to Salicaceae constructed based on their chloroplast genomes with 5000 bootstrap replicates. Populus trichocarpa Torr. \& A.Gray ex Hook. and Populus euphratica Olivier were used as the outgroups. Bootstrap values are shown at branch nodes (only bootstrap values $<100 \%$ were shown). Accession numbers: Salix magnifica Hemsl. NC037424, Salix hypoleuca Seemen NC037423, Salix rorida NC037428, Salix rehderiana NC037427, Salix viminalis L. MN117720, Salix koriyanagi Kimura ex Goerz NC044419, Salix psammophila MN495627, Salix suchowensis NC026462, Salix babylonica L. NC028350, Salix oreinoma C.K.Schneid. NC035743, Salix brachista C.K.Schneid. CM018592, Salix triandra L. MK722343, Salix tetrasperma Roxb. NC035744, Salix paraplesia C.K.Schneid. NC037426, Salix gracilistyla Miq. NC043878, Salix taoensis Goerz ex Rehder \& Kobuski NC037429, Salix chaenomeloides Kimura NC037422, Salix minjiangensis N.Chao NC037425, Populus euphratica NC024747, Populus trichocarpa NC009143. The three species used in this study are bold marked.

\section{Conclusions}

In this study, the whole chloroplast genomes of S. annulifera, S. cupularis, and S. spathulifolia were obtained by next-generation sequencing. Our results showed that the genomes ranged from 155,566 to 155,680 bp in length, encoding 130 genes. Comparison among these three willows' cp genomes showed similarity in their structure and organization. Phylogenetic analysis revealed that Salix spathulifolia, S. cupularis, and S. annulifera could be found within one clade among all studied Salix species. S. spathulifolia was located at the base of the clade, S. annulifera was sister to $S$. rorida, and $S$. cupularis was closest to $S$. suchowensis and S. psammophila. The complete cp genomes of these three willows may provide an opportunity for further molecular phylogenetic and evolutionary studies in Salicaceae. 
Supplementary Materials: The following are available online at https:/ / www.mdpi.com/article/ $10.3390 / \mathrm{f} 12121681 / \mathrm{s} 1$, Table S1: The length and number of different repetitive units in the genomes of Salix spathulifolia, S. cupularis, and S. annulifera; Table S2: The size, position, and type of repeats in the chloroplast genomes of S. spathulifolia, S. cupularis, and S. annulifera.

Author Contributions: Z.-X.Z. and K.-J.L. conceived and designed the study; K.-J.L. prepared the samples and performed the experiments; X.-J.Z. analyzed the data and prepared the initial draft; Y.-C.W., J.H. and Y.-M.W. reviewed and edited the final manuscript; Z.-X.Z. supervised the study. All authors have read and agreed to the published version of the manuscript.

Funding: This research was funded by National Natural Science Foundation of China (grant no. 31620103902).

Institutional Review Board Statement: Not applicable.

Informed Consent Statement: Not applicable.

Data Availability Statement: The three assembled chloroplast genomes in our study were deposited in GenBank under the accession numbers (MZ365445, MZ365446, MZ365447). The raw data supporting the results of this study were deposited in NCBI at https: / / www.ncbi.nlm.nih.gov (accessed on 1 October 2021) (SRR16018732, SRR16018727, SRR16018692).

Acknowledgments: We would like to thank the participants for their contributions to this study, and research foundation from Zhejiang Xianxialing nature reserve administration was acknowledged. We also appreciate the help from Fei-Yi Guo for the field investigation.

Conflicts of Interest: The authors declare no conflict of interest.

\section{References}

1. Francisco-Ortega, J.; Wang, F.G.; Wang, Z.S.; Xing, F.W.; Liu, H.; Xu, H.; Xu, W.X.; Luo, Y.B.; Song, X.Q.; Gale, S.; et al. Endemic seed plant species from Hainan Island: A checklist. Bot. Rev. 2010, 76, 295-345. [CrossRef]

2. Drouin, G.; Daoud, H.; Xia, J. Relative rates of synonymous substitutions in the mitochondrial, chloroplast and nuclear genomes of seed plants. Mol. Phylogenet. Evol. 2008, 49, 827-831. [CrossRef]

3. Palmer, J.D. Comparative organization of chloroplast genomes. Annu. Rev. Genet. 1985, 19, 325-354. [CrossRef]

4. Fan, W.B.; Wu, Y.; Yang, J.; Shahzad, K.; Li, Z.H. Comparative chloroplast genomics of dipsacales species: Insights into sequence variation, adaptive evolution, and phylogenetic relationships. Front. Plant Sci. 2018, 9, 689. [CrossRef]

5. Wicke, S.; Schneeweiss, G.M.; de Pamphilis, C.W.; Müller, K.F.; Quandt, D. The evolution of the plastid chromosome in land plants: Gene content, gene order, gene function. Plant Mol. Biol. 2011, 76, 273-297. [CrossRef] [PubMed]

6. Jansen, R.K.; Raubeson, L.A.; Boore, J.L.; de Pamphilis, C.W.; Chumley, T.W.; Haberle, R.C.; Wyman, S.K.; Alverson, A.J.; Peery, R.; Herman, S.J.; et al. Methods for obtaining and analyzing whole chloroplast genome sequences. Methods Enzymol. 2005, 395, 348-384. [CrossRef] [PubMed]

7. Sloan, D.B.; Triant, D.A.; Forrester, N.J.; Bergner, L.M.; Wu, M.; Taylor, D.R. A recurring syndrome of accelerated plastid genome evolution in the angiosperm tribe Sileneae (Caryophyllaceae). Mol. Phylogenetics Evol. 2014, 72, 82-89. [CrossRef]

8. Wang, Y.G. Natural hybridization and speciation. Biodivers. Sci. 2017, 25, 565-576. [CrossRef]

9. Ellis, R.J. The Plastids: Their Chemistry, Structure, Growth and Inheritance, 2nd ed.; JTO Kirk and RAE Tilney-Bassett, Elsevier/NorthHolland Biomedical Press: Amsterdam, The Netherlands; New York, NY, USA; Oxford, UK, 1978.

10. Kuroiwa, T. The replication, differentiation, and inheritance of plastids with emphasis on the concept of organelle nuclei. Int. Rev. Cytol. 1991, 128, 1-62. [CrossRef]

11. Flora of North America Editorial Committee. Flora of North America: Volume 7 Magnoliophyta: Salicaceae to Brassicaceae; Oxford University Press: Oxford, UK, 2010.

12. Wu, Z.Y.; Raven, P.H. Flora of China; Missouri Botanical Garden Press: St. Louis, MO, USA, 1999; Volume 4.

13. Skvortsov, A.K. Willows of Russia and Adjacent Countries: Taxonomical and Geographic Revision (Translated by n. Kadis, 1999); Joensuu University: Joensuu, Finland, 1999.

14. Fang, Z.F. On the distribution and origin of Salix in the world. J. Syst. Evol. 1987, 25, 307-313.

15. Myers-Smith, I.H.; Forbes, B.C.; Wilmking, M.; Hallinger, M.; Lantz, T.; Blok, D.; Tape, K.D.; Macias-Fauria, M.; Sass-Klaassen, U.; Lévesque, E.; et al. Shrub expansion in tundra ecosystems: Dynamics, impacts and research priorities. Environ. Res. Lett. 2011, 6, 045509. [CrossRef]

16. Smart, L.B.; Volk, T.A.; Lin, J.; Kopp, R.F.; Phillips, I.S.; Cameron, K.D.; White, E.H.; Abrahamson, L.P. Genetic improvement of shrub willow (Salix spp.) crops for bioenergy and environmental applications in the United States. Unasylva 2005, 56, 51.

17. Argus, G.W. The genus Salix (Salicaceae) in the southeastern United States. Syst. Bot. Monogr. 1986, 9, 1-170. [CrossRef]

18. Zhao, S.D. Distribution of Willows (Salix) in China. J. Syst. Evol. 1987, 25, 114-124. 
19. Zhang, M.L. Studies on the distribution and differentiation of Willows (Salix) in Qinling Mountain. Bull. Bot. Res. 1993, 13, 136-145.

20. Chen, J.H.; Sun, H.; Wen, J.; Yang, Y.P. Molecular phylogeny of Salix L. (Salicaceae) inferred from three chloroplast datasets and its systematic implications. Taxon 2010, 59, 29-37. [CrossRef]

21. Lumbsch, H.T.; Lauron-Moreau, A.; Pitre, F.E.; Argus, G.W.; Labrecque, M.; Brouillet, L. Phylogenetic relationships of American Willows (Salix L., Salicaceae). PLoS ONE 2015, 10, e0121965. [CrossRef]

22. Azuma, T.; Kajita, T.; Yokoyama, J.; Ohashi, H. Phylogenetic relationships of Salix (Salicaceae) based on $r b c L$ sequence data. Am. J. Bot. 2000, 87, 67-75. [CrossRef]

23. Barkalov, V.Y.; Kozyrenko, M.M. Phylogenetic relationships of Salix L. Subg. Salix species (Salicaceae) according to sequencing data of intergenic spacers of the chloroplast genome and its rDNA. Russ. J. Genet. 2014, 50, 828-837. [CrossRef]

24. Li, J.; Zhuo, Z.; Xu, D.; Yang, H.; Zhu, T. The complete chloroplast genome of Salix cupularis rehder, a sand binder in alpine hillslope, China. Mitochondrial DNA Part B 2021, 6, 2519-2520. [CrossRef]

25. Hu, Y.F.; Shu, X.Y.; He, J.; Zhang, Y.L.; Xiao, H.H.; Tang, X.Y.; Gu, Y.F.; Lan, T.; Xia, J.G.; Ling, J.; et al. Storage of C, N, and $\mathrm{P}$ affected by afforestation with Salix cupularis in an alpine semiarid desert ecosystem. Land Degrad. Dev. 2018, 29, 188-198. [CrossRef]

26. Gulyaev, S.; Cai, X.-J.; Guo, F.-Y.; Kikuchi, S.; Wendy, L.; Zhang, Z.-X.; Hörandl, E.; He, L. The phylogeny of Salix revealed by whole genome re-sequencing suggests different sex-determination systems in major groups of the genus. Ann. Bot. 2021. submitted.

27. Chen, S.; Zhou, Y.; Chen, Y.; Gu, J. Fastp: An ultra-fast all-in-one fastq preprocessor. Bioinformatics 2018, 34, i884-i890. [CrossRef]

28. Kearse, M.; Moir, R.; Wilson, A.; Stones-Havas, S.; Cheung, M.; Sturrock, S.; Buxton, S.; Cooper, A.; Markowitz, S.; Duran, C.; et al. Geneious basic: An integrated and extendable desktop software platform for the organization and analysis of sequence data. Bioinformatics 2012, 28, 1647-1649. [CrossRef]

29. He, J.; Yao, M.; Lyu, R.D.; Lin, L.L.; Liu, H.J.; Pei, L.Y.; Yan, S.X.; Xie, L.; Cheng, J. Structural variation of the complete chloroplast genome and plastid phylogenomics of the genus Asteropyrum (Ranunculaceae). Sci. Rep. 2019, 9, 15285. [CrossRef]

30. Huang, Y.; Wang, J.; Yang, Y.; Fan, C.; Chen, J. Phylogenomic analysis and dynamic evolution of chloroplast genomes in Salicaceae. Front. Plant Sci. 2017, 8, 1050. [CrossRef]

31. Qu, X.J.; Moore, M.J.; Li, D.Z.; Yi, T.S. PGA: A software package for rapid, accurate, and flexible batch annotation of plastomes. Plant Methods 2019, 15, 50. [CrossRef]

32. Wu, Z.Q. The whole chloroplast genome of shrub Willows (Salix suchowensis). Mitochondrial DNA Part A 2016, $27,2153-2154$. [CrossRef] [PubMed]

33. Huang, D.I.; Cronk, Q.C. Plann: A command-line application for annotating plastome sequences. Appl. Plant Sci. 2015, 3, 1500026. [CrossRef]

34. Greiner, S.; Lehwark, P.; Bock, R. OrganellarGenomeDRAW (ogdraw) version 1.3.1: Expanded toolkit for the graphical visualization of organellar genomes. Nucleic Acids Res. 2019, 47, W59-W64. [CrossRef]

35. Beier, S.; Thiel, T.; Münch, T.; Scholz, U.; Mascher, M. MISA-web: A web server for microsatellite prediction. Bioinformatics 2017, 33, 2583-2585. [CrossRef]

36. Kurtz, S.; Choudhuri, J.V.; Ohlebusch, E.; Schleiermacher, C.; Stoye, J.; Giegerich, R. REPuter: The manifold applications of repeat analysis on a genomic scale. Nucleic Acids Res. 2001, 29, 4633-4642. [CrossRef] [PubMed]

37. Kumar, S.; Stecher, G.; Tamura, K. Mega7: Molecular evolutionary genetics analysis version 7.0 for bigger datasets. Mol. Biol. Evol. 2016, 33, 1870-1874. [CrossRef]

38. Amiryousefi, A.; Hyvönen, J.; Poczai, P. IRscope: An online program to visualize the junction sites of chloroplast genomes. Bioinformatics 2018, 34, 3030-3031. [CrossRef] [PubMed]

39. Rozas, J.; Ferrer-Mata, A.; Sánchez-DelBarrio, J.C.; Guirao-Rico, S.; Librado, P.; Ramos-Onsins, S.E.; Sánchez-Gracia, A. DnaSP 6: DNA Sequence Polymorphism Analysis of Large Data Sets. Mol. Biol. Evol. 2017, 34, 3299-3302. [CrossRef] [PubMed]

40. Frazer, K.A.; Pachter, L.; Poliakov, A.; Rubin, E.M.; Dubchak, I. VISTA: Computational tools for comparative genomics. Nucleic Acids Res. 2004, 32, W273-W279. [CrossRef] [PubMed]

41. Katoh, K.; Rozewicki, J.; Yamada, K.D. MAFFT online service: Multiple sequence alignment, interactive sequence choice and visualization. Brief. Bioinform. 2019, 20, 1160-1166. [CrossRef] [PubMed]

42. Zhang, D.; Gao, F.; Jakovlić, I.; Zou, H.; Zhang, J.; Li, W.X.; Wang, G.T. PhyloSuite: An integrated and scalable desktop platform for streamlined molecular sequence data management and evolutionary phylogenetics studies. Mol. Ecol. Resour. 2020, 20, 348-355. [CrossRef] [PubMed]

43. Kalyaanamoorthy, S.; Minh, B.Q.; Wong, T.K.F.; von Haeseler, A.; Jermiin, L.S. ModelFinder: Fast model selection for accurate phylogenetic estimates. Nat. Methods 2017, 14, 587-589. [CrossRef]

44. Redwan, R.M.; Saidin, A.; Kumar, S.V. Complete chloroplast genome sequence of MD-2 pineapple and its comparative analysis among nine other plants from the subclass Commelinidae. BMC Plant Biol. 2015, 15, 196. [CrossRef]

45. Hu, Y.; Woeste, K.E.; Zhao, P. Completion of the chloroplast genomes of five Chinese Juglans and their contribution to chloroplast phylogeny. Front. Plant Sci. 2017, 7, 1955. [CrossRef] [PubMed]

46. Wang, W.; Yu, H.; Wang, J.; Lei, W.; Gao, J.; Qiu, X.; Wang, J. The complete chloroplast genome sequences of the medicinal plant Forsythia suspensa (Oleaceae). Int. J. Mol. Sci. 2017, 18, 2288. [CrossRef] [PubMed] 
47. Liu, X.F.; Zhu, G.F.; Li, D.M.; Wang, X.J. Complete chloroplast genome sequence and phylogenetic analysis of Spathiphyllum 'Parrish'. PLoS ONE 2019, 14, e0224038. [CrossRef] [PubMed]

48. Yang, J.B.; Tang, M.; Li, H.T.; Zhang, Z.R.; Li, D.Z. Complete chloroplast genome of the genus Cymbidium: Lights into the species identification, phylogenetic implications and population genetic analyses. BMC Evol. Biol. 2013, 13, 84. [CrossRef] [PubMed]

49. Chen, Y.; Hu, N.; Wu, H. Analyzing and characterizing the chloroplast genome of Salix wilsonii. BioMed Res. Int. 2019, 2019, 5190425. [CrossRef]

50. Lyons-Weiler, J.; Hoelzer, G.A.; Tausch, R.J. Optimal outgroup analysis. Biol. J. Linn. Soc. 2008, 64, 493-511. [CrossRef]

51. Wheeler, W.C. Nucleic acid sequence phylogeny and random outgroups. Cladistics 1990, 6, 363-367. [CrossRef]

52. Huelsenbeck, J.P.; Bollback, J.P.; Levine, A.M. Inferring the root of a phylogenetic tree. Syst. Biol 2002, 51, 332-343. [CrossRef]

53. Yang, Z.; Rannala, B. Molecular phylogenetics: Principles and practice. Nat. Rev. Genet. 2012, 13, 303-314. [CrossRef]

54. Rechinger, K.H. Salix taxonomy in Europe-Problems, interpretations, observations. Proc. R. Soc. Edinb. 1992, 98, 1-12. [CrossRef] 